\title{
EGU21-9277
}

https://doi.org/10.5194/egusphere-egu21-9277

EGU General Assembly 2021

(c) Author(s) 2021. This work is distributed under

the Creative Commons Attribution 4.0 License.

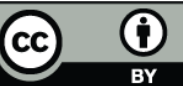

\section{HydroSHEDS v2.0 - Refined global river network and catchment delineations from TanDEM-X elevation data}

\author{
Bernhard Lehner ${ }^{1,2}$, Achim Roth $^{3}$, Martin Huber ${ }^{3}$, Mira Anand ${ }^{2}$, Günther Grill ${ }^{2}$, Nicole Osterkamp ${ }^{3}$, \\ Raphael Tubbesing ${ }^{3}$, Leena Warmedinger ${ }^{3}$, and Michele Thieme ${ }^{4}$ \\ ${ }^{1}$ Geography, McGill University, Montreal, Canada (bernhard.lehner@mcgill.ca) \\ ${ }^{2}$ Confluvio Consulting, Montreal, Canada \\ ${ }^{3}$ German Remote Sensing Data Center (DFD) at German Aerospace Center (DLR), Oberpfaffenhofen, Germany \\ ${ }^{4}$ World Wildlife Fund US, Washington, DC, USA
}

Since its introduction in 2008, the HydroSHEDS database (www.hydrosheds.org) has transformed large-scale hydro-ecological research and applications worldwide by offering standardized spatial units for hydrological assessments. At its core, HydroSHEDS provides digital hydrographic information that can be applied in Geographic Information Software (GIS) or hydrological models to delineate river networks and catchment boundaries at multiple scales, from local to global. Its various data layers form the basis for applications in a wide range of disciplines including environmental, conservation, socioeconomic, human health, and sustainability studies.

Version 1 of HydroSHEDS was derived from the digital elevation model of the Shuttle Radar Topography Mission (SRTM) at a pixel resolution of 3 arc-seconds ( 90 meters at the equator). It was created using customized processing and optimization algorithms and a high degree of manual quality control. Results are available at varying resolutions, ranging from 3 arc-seconds $(\sim 90 \mathrm{~m})$ to 5 minutes $(\sim 10 \mathrm{~km})$, and in nested sub-basin structures, making the data uniquely suitable for applications at multiple scales. A suite of related data collections and value-added information, foremost the HydroATLAS compilation of over 50 hydro-environmental attributes for every river reach and sub-basin, continuously enhance the versatility of the HydroSHEDS family of products. Yet version 1 of HydroSHEDS shows some important limitations. In particular, coverage above $60^{\circ}$ northern latitude (i.e., largely the Arctic) is missing for the 3 arc-second product and is of low quality for coarser products because no SRTM elevation data are available for this region. Also, some areas are affected by inherent data gaps or other errors that could not be fully resolved at the time of creating version 1 of HydroSHEDS.

Today, the TanDEM-X dataset (TerraSAR-X add-on for Digital Elevation Measurement), created in partnership between the German Aerospace Agency (DLR) and Airbus, offers a new digital elevation model covering the entire global land surface including northern latitudes. In a collaborative project, this dataset is used to extract HydroSHEDS v2.0, following the same basic specifications as version 1 . DLR is processing the original $12 \mathrm{~m}$ resolution TanDEM-X data to create a hydrologically pre-conditioned version at 3 arc-second resolution. In this step, corrections with 
high-resolution vegetation and settlement maps are applied to reduce distortions caused by vegetation cover and in built-up areas. Following this preprocessing, refined hydrological optimization and correction algorithms are used to derive the drainage pathways, including improved 'stream-burning' techniques that incorporate recent data products such as highresolution terrestrial open water masks and improved tracing of drainage pathways as center lines in global lake and river maps. The resulting HydroSHEDS v2.0 database will provide river networks and catchment boundaries at full global coverage. Release of the data under a free license is scheduled for 2022, with regions above $60^{\circ}$ northern latitude being completed first in 2021. 